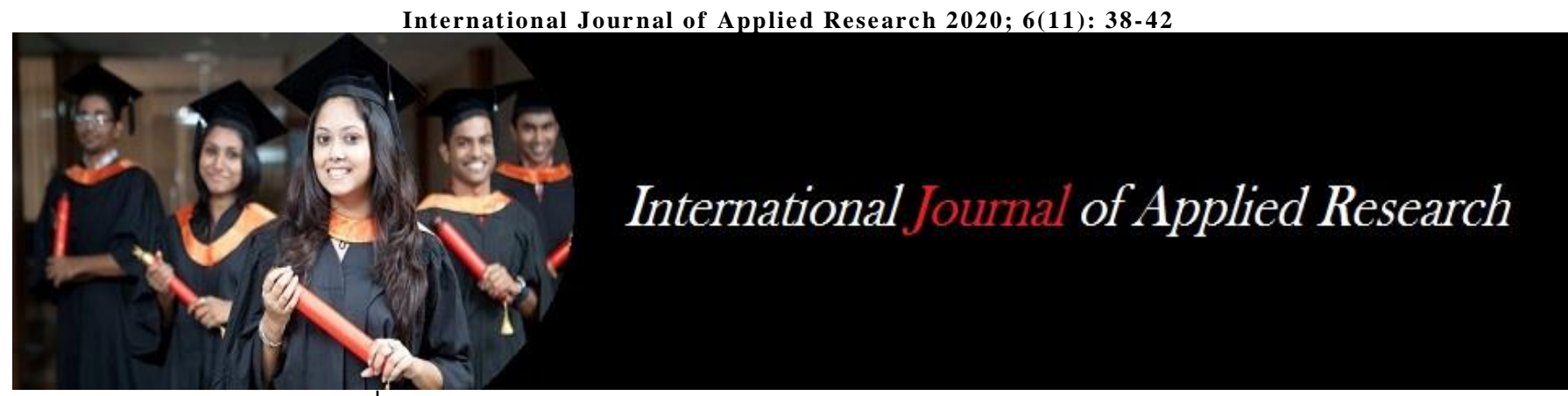

ISSN Print: 2394-7500 ISSN Online: 2394-5869 Impact Factor: 8.4

IJAR 2020; 6(11): 38-42 www.allresearchjournal.com

Received: 28-09-2020 Accepted: 30-10-2020

Mahendra Pratap Singh Department of Chemistry, Shri Sadguru Saibaba Science College, Ashti, Gadchiroli,

Maharashtra, India
Corresponding Author: Mahendra Pratap Singh Department of Chemistry, Shri Sadguru Saibaba Science College, Ashti, Gadchiroli, Maharashtra, India

\section{Synthesis, characterisation and Electrochemical studies of transition metal CO(II) complexes of Mannich bases from newly synthesised Schiff bases ligand}

\section{Mahendra Pratap Singh}

DOI: https://doi.org/10.22271/allresearch.2020.v6.i11a.7741

\begin{abstract}
The present study carried out by the preparation of Mannich base $\mathrm{MB}_{1}$ and $\mathrm{MB}_{2}$ ligand by the reduction of newly synthesized Schiff bases from furfuraldehyde with sulphacetamide/sulphanilamide, and their $\mathrm{CO}$ (II) metal complexes with preferred metal chloride/metal sulphate salt in ethanol with 2:1 molar ratio. All the complexes are found to be as colored solids. Which are characterized with the help of magnetic moment and electrochemical studies.
\end{abstract}

Keywords: Mannich bases, Schiff bases, transition metal complexes, electrochemical studies

\section{Introduction}

Many structure of hetrocycles having importance in drug design and synthesis is an important role in bioinorganic and medicinal chemistry. Compound containing hetrocyclic structures found to be high degree of binding affinity to biological system ${ }^{[1]}$, and have been reported to consists pronounced pharmacological, analytical and industrial uses ${ }^{[2-3]}$. In past some decades, researchers have interest towards transition metal complexes of hetrocyclic aromatic Schiff bases bearing nitrogen, oxygen and sulphur donar atoms due to their therapatic importance ${ }^{[4-5]}$. Metal complexes of amide moiety have been studied extensively recent years due to the selectivity and sensivity of the Mannich base ligands towards various ions $^{6-11}$, and exhibit a variety of biological activities such as antibacterial, antifungal, anti T.B. activity, anti HIV activity, antiviral, antiulcer and antihypertensive ${ }^{[12-18]}$. The present studies have been completed by the reduction of Sciff base ligands through the reaction with heterocyclic compound like furfuraldehyde and sulpha drugs such as sulphacetamide /sulphanilamide in alcoholic solution.

\section{Experimental}

All of the used chemicals were analytical grade (Merch, BDH, S.D. Fine's and Sisco chemicals). The other chemical and solvent were used after purification by distillation, and metal salts used, were as such. The elemental analysis of carbon hydrogen and nitrogen was done on at R.S.I.C. Chandigarh. Estimation of sulphur in ligand and complexes were determined by standard method [19], and estimation of halogen by volhard's methods as ionized form as silver chloride ${ }^{[20]}$ gravimetrically. The metal percentage in CO (II) metal complexes were determined by standard method ${ }^{[21-25]}$, magnetic measurements of the prepared complexes were taken at room temperature on EG \& G model 155 VSM at RSIC, IIT-madras, infrared spectra of ligand $\mathrm{MB}_{1}$ and $\mathrm{MB}_{2}$ and their chloro/sulphato complexes were studied on Perkin Elmer Spectrometer in the FT-IR region using $\mathrm{KBr}$ pellets at RSIC, Chandigarh and Alembic Ltd. Vadodara. Electronic spectra were recorded on ELISCO SL 171 Spectrophotometer by dissolving in (EtOH/DMF) at room temperature in, chemistry department, RBS College, Agra. Mass spectra of ligand $\mathrm{MB}_{1}$ and $\mathrm{MB}_{2}$ was carried out on MASPEC System (MSW/9629) using $200{ }^{\circ} \mathrm{C}$ intel temperature at RSIC, IIT-Madras. 


\section{Synthesis of Mannich base $\mathrm{C}_{13} \mathrm{H}_{14} \mathrm{~N}_{2} \mathrm{O}_{4} \mathrm{~S}$ (MB $\left.{ }_{1}\right)$} $\mathrm{C}_{11} \mathrm{H}_{12} \mathrm{~N}_{2} \mathrm{O}_{3} \mathrm{~S}\left(\mathrm{MB}_{2}\right)$ Ligand

The above ligands were synthesise by refluxing sulphacetamide/sulphanilamide (10mmol, 2.14gm in $25 \mathrm{ml}$ $\mathrm{EtOH} / 1.72 \mathrm{gm}$ in methanol) with furfural (10mmol, $0.96 \mathrm{ml}$ in $25 \mathrm{ml} \mathrm{EtOH} / \mathrm{Methanol}$ respectively) on water bath for 3-4 hours with stirring. The obtained product, cooled at $0{ }^{\circ} \mathrm{C}$ and sodium borohydried (10mmol, $0.39 \mathrm{gm}$ ) added over a period of 1-2 hours and stirred over a period of two hours, slowly the temperature was raised to room temperature and put it for 14-15 hour for evaporating of the solvent and then recrystallised with ethanol /acetone and dried in air, deep yellow/reddish yellow crystals of $\mathrm{MB}_{1}$ and $\mathrm{MB}_{2}$ ligand was obtained. Above ligand hace been synthesise on behaf of known methods ${ }^{[26-28]}$.

The analytical and mass spectral data obtained for the ligand $\mathrm{MB}_{1} / \mathrm{MB}_{2}$ are representing below.

\section{Analysis calculated for $\mathrm{C}_{13} \mathrm{H}_{14} \mathrm{~N}_{2} \mathrm{O}_{4} \mathrm{~S} / \mathrm{C}_{11} \mathrm{H}_{12} \mathrm{O}_{3} \mathbf{N}_{2} \mathrm{~S}$}

C 53.04/52.36, H 4.79/4.79, N 9.51/19.02, S10.89/12.70\% Found; C 52.86/52.26, H 4.86/4.68, N9.48/19.13, S 10.96/12.74:Mass (m/z) 304/254, fragmented at m/e 57, 81,
100, 139, 165, 227, 250, 265, 295 and 304 with a higher peak at 193 for $\mathrm{MB}_{1}$, and the fragmented intensities at $\mathrm{m} / \mathrm{e}$ 53, 65, 76, 96, 108, 130, 140, 156, 172, 174, 211, 224, 236, 252 and 254 with highest peak at 81 for $\mathrm{MB}_{2}$ ligand.

\section{Synthesis of Metal Complexes}

The cobalt chloride/cobalt sulphate $(5 \mathrm{mmol}$ in $25 \mathrm{ml}$ ethanol), was added slowly to a alcoholic solution of ligand $\mathrm{MB}_{1} / \mathrm{MB}_{2}$ (10mmol).The resulting mixture was stirred for half an hour and then refluxed for 2-3 hour on a water bath and then cooled the product and standing for evaporation slowly, washed and dried. The different colored crystals of different complexes with different metal salts and ligands in 1:2 metal ligand molar ratio, have been isolated and subjected to electrochemical studies.

\section{Result and Discussion}

All the complexes are soluble in ethanol, DMF and DMSO having low melting points. The analytical data reveales 1:2 metal: ligand stereochemistry for all these complexes. The analytical data is given in table- 2

Table 1: Electronic Septracal studies of Cobalt (II) Complexes

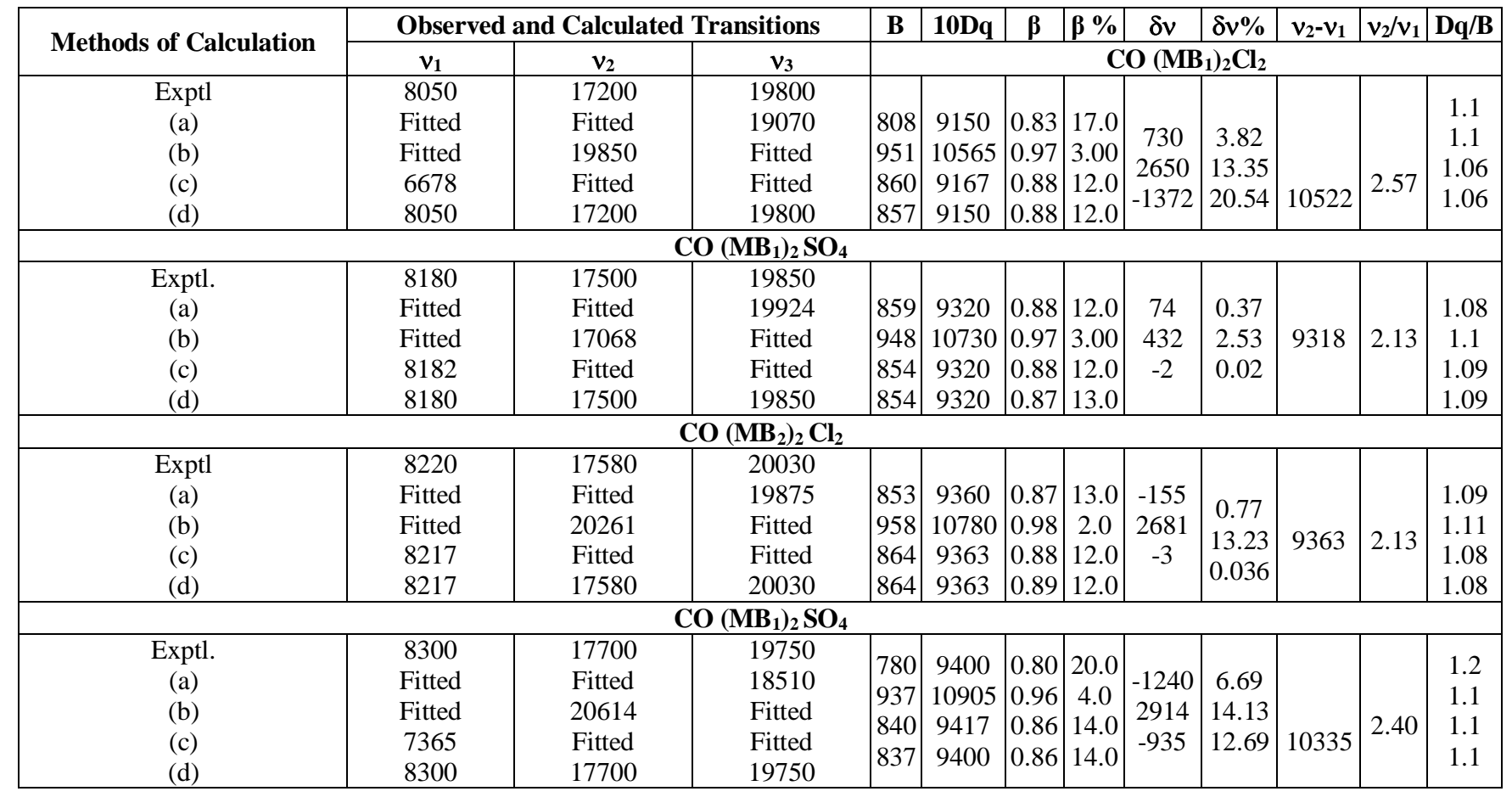

Table 2: Analytical estimations and magnetic moment value of the Mannich base complexes

\begin{tabular}{|c|c|c|c|c|c|c|c|c|c|}
\hline \multirow{2}{*}{ Metal Complexes } & \multirow{2}{*}{ Colour } & \multirow{2}{*}{ EFF (B.M) } & \multicolumn{7}{|c|}{ Analytical (\%) found/Calcd } \\
\hline & & & $\mathrm{C} \%$ & $\mathbf{H \%}$ & $\mathbf{0 \%}$ & $\mathbf{N \%}$ & $\mathbf{S \%}$ & CI\% & M\% \\
\hline \multirow{2}{*}{$\mathrm{CO}\left(\mathrm{MB}_{1}\right)_{2} \mathrm{Cl}_{2}$} & \multirow{2}{*}{ Pinkish Brown } & \multirow{2}{*}{4.5} & 43.52 & 3.9 & 19.74 & 7.84 & 8.88 & 9.8 & 8.3 \\
\hline & & & 43.46 & 3.92 & 17.81 & 7.79 & 8.92 & 9.86 & 8.2 \\
\hline \multirow{2}{*}{$\mathrm{CO}\left(\mathrm{MB}_{1}\right)_{2} \mathrm{SO}_{4}$} & \multirow{2}{*}{ Reddish Black } & \multirow{2}{*}{4.8} & 42.01 & 3.8 & 25.78 & 7.5 & 12.9 & - & 7.9 \\
\hline & & & 41.99 & 3.79 & 25.81 & 7.53 & 12.93 & - & 7.92 \\
\hline \multirow{2}{*}{$\mathrm{CO}\left(\mathrm{MB}_{2}\right)_{2} \mathrm{Cl}_{2}$} & \multirow{2}{*}{ Yellowish Brown } & \multirow{2}{*}{4.75} & 41.6 & 3.83 & 15.1 & 8.85 & 10.12 & 11.18 & 9.28 \\
\hline & & & 41.64 & 3.8 & 15.13 & 8.83 & 10.1 & 11,0 & 9.28 \\
\hline \multirow{2}{*}{$\mathrm{CO}\left(\mathrm{MB}_{2}\right)_{2} \mathrm{SO}_{4}$} & \multirow{2}{*}{ Reddish Brown } & \multirow{2}{*}{5.1} & 39.99 & 3.71 & 24.22 & 8.54 & 14.56 & - & 8.95 \\
\hline & & & 40.06 & 3.66 & 24.25 & 8.49 & 14.58 & - & 8.8 \\
\hline
\end{tabular}

\section{Magnetic Measurement}

The present four CO (II) metal complexes show magnetic moment values in the range 4.5 to 5.1 B.M., Which is higher than the spin only value of 3.89 B.M. due to the orbital contribution. These complexes are expected to have octahedral geometry, can be explained on the basis of octahedral symmetry involving a high degree of orbital 
contribution due to the three fold degeneracy of the ${ }^{[4]} \mathrm{T}_{1} \mathrm{~g}$ ground state.

\section{Electronic Spectral Studies}

$\mathrm{CO}$ (II) forms a great variety of structural environment, due to this, the electronic structure, thus the spectral and magnetic properties of the ion, are extremely varied. The beautiful pink to red brown color of octahedral coordinated oxygen ligated CO (II), as distinguished from the blue color of tetrahedrally ligated $\mathrm{CO}$ (II) is well known to every chemist. In present study, we will going to discuss the electronic spectra of CO (II) complexes of Mannich base ligand $\mathrm{MB}_{1} / \mathrm{MB}_{2}$ in detailed. The electronic spectra of isolated $\mathrm{CO}$ (II) complexes showed the presence of these bands given in table-1, Which may be assigned to the transition ${ }^{4} \mathrm{~T}_{1} \mathrm{~g} \rightarrow{ }^{4} \mathrm{~T}_{2} \mathrm{~g}(\mathrm{~F})\left(\mathrm{v}_{1}\right),{ }^{4} \mathrm{~T}_{1} \mathrm{~g} \rightarrow{ }^{4} \mathrm{~A}_{2} \mathrm{~g}\left(\mathrm{v}_{2}\right)$ and ${ }^{4} \mathrm{~T}_{1} \mathrm{~g} \rightarrow$ (P) $\left(v_{3}\right)$, in order to increasing energy. The increased intensity of these bands indicate some tetragonal distortion and the possision of the bands closely resemble with the spectra of the other distorted octahedral CO (II) complexes [44]. The crystal field splitting energy (10Dq) and Racah interelectronic parameter (B) for the present $\mathrm{CO}$ (II) complexes were calculated by using the following equation [29]. The value of transitions $v_{1}, v_{2}$ and $v_{3}$ may be obtained by using Konig's equation ${ }^{[30]}$.

The spectral data and values of various ligand field parameters such as $v_{1}, v_{2}, v_{3}, \mathrm{~B}, \mathrm{C}, \mathrm{F}^{2}, \mathrm{~F}^{4}, 10 \mathrm{Dq}, \mathrm{f}, \mathrm{h}, \beta, \beta \%$, $v_{3} / v_{1}$ and $v_{3} / v_{2}$ are given in table-3, and significance of these parameters is given in literature ${ }^{[31-34]}$. The value of above mentioned parameters are in close agreement with the reported value for $\mathrm{CO}$ (II) complexes, having distorted octahedral geometry. In present study, we will report the results of the mean and exact spin-pairing energy of the newly prepared four CO (II) complexes with octrahedral geometry ${ }^{[35-40]}$ by using following equation for $\mathrm{d}^{4}$ ion.

$\Pi=4 \mathrm{~B}+4 \mathrm{C}-60 \mathrm{~B}^{2} / 10 \mathrm{Dq}+\mathrm{X}$

Where, $\mathrm{X}=-4.5 \mathrm{~B}-5 \mathrm{Dq} \pm 1 / 2(225 \mathrm{~B} 2+100 \mathrm{Dq} 2+180$ Dq.B) $1 / 2$

In fact, in $\mathrm{d}^{7}$ configuration $4 \mathrm{~T} 1 \mathrm{~g}\left(\mathrm{t}^{5}{ }_{2} \mathrm{~g} \mathrm{e}^{2} \mathrm{~g}\right)$ mixes with three different $2 \mathrm{Eg}$ terms according to this exact spin pairing energies (П) can be calculated with the help of following equation.

$\Pi=4 \mathrm{~B}+4 \mathrm{C}$

$\Pi / \mathrm{B}=0.3594 \gamma+0.5051$
The value of $\Pi$ and $\Pi$ /B for the newly prepared CO (II) complexes are given in table-3

\section{3-Infrared Spectral Studies:}

Important IR frequencies and their tentative assignment are given in table- 4 . The, Mannich base ligand $\mathrm{MB}_{1}$ shows the IR spectrum band at $3380 \mathrm{~cm}^{-1}$ characteristic of streaching vibration of $v \mathrm{~N}-\mathrm{H}$ of $-\mathrm{CH}_{2}-\mathrm{NH}<$ group. These bands have shifted in the spectra of both chloro / sulphato complexes, showing the involvement of nitrogen of this group in complexation. The new bands at $540-541 \mathrm{~cm}^{-1}$ are assigned to $v$ (M-N) stretching ${ }^{[41-42]}$ indicating the coordination through nitrogen with $\mathrm{CO}$ (II) ion. A stretching band observed at $1268 \mathrm{~cm}^{-1}$ due to $v(\mathrm{C}-\mathrm{O}-\mathrm{C})$ of hetrocyclic furan ring in the above ligand and band appeared at $1230-1244 \mathrm{~cm}^{-}$ 1 in both complexes, suggestive of the coordination of oxygen atom of $v(\mathrm{C}-\mathrm{O}-\mathrm{C})$ with cobalt metal ion. The low frequency bands appeared at $682-681 \mathrm{~cm}^{-1}$ due to $v(\mathrm{M}-\mathrm{O})$ also suggest 43 the coordination through furyl oxygen. Another band appeared at $1708-1703 \mathrm{~cm}^{-1}$ in ligand and also in the complexes at the same position due to - CO-NHgroup, indicating the noninvolvement in coordination.

The new band appeared at $310 \mathrm{~cm}^{-1}$ and $339 \mathrm{~cm}^{-1}$ in complexation due to $v(\mathrm{M}-\mathrm{Cl})$ and $v(\mathrm{M}-\mathrm{S})$ stretching modes respectively. The appeared band at $1090 \mathrm{~cm}^{-1}$ and $627 \mathrm{~cm}^{-1}$ in sulphato complex [CO $\left.\left(\mathrm{MB}_{1}\right) \mathrm{SO}_{4}\right]$, may be assigned sulphate moeity in complexation. The IR spectra of CO (II) complexes indicate nature through furfuryl oxygen and methylamine nitrogen sites. The IR spectra of ligand $\mathrm{MB}_{2}$ shows the band at $3350 \mathrm{~cm}^{-1}$, assigned to the $v \mathrm{~N}-\mathrm{H}$ frequency. This band get shifted to higher frequencies in the IR spectra of complexes thereby, indicating the involvement of nitrogen of $-\mathrm{CH}_{2}-\mathrm{NH}$ - group in bonding with metal.

The strong band appeared at $3269 \mathrm{~cm}^{-1}$, may be due to $\mathrm{SO}_{2}-\mathrm{NH}$ - group to $v \mathrm{~N}-\mathrm{H}$. In the present complexes, this band is disappeared, indicating the participation of nitrogen in coordination. The coordination of nitrogen is also confirmed by the presence of a low frequency band at (542$\left.540 \mathrm{~cm}^{-1}\right)^{41-42]}$ assigned to $v \mathrm{M}-\mathrm{N}$ stretching. The ligand observed a band at $1040 \mathrm{~cm}^{-1}$; may be assigned to $\mathrm{vC}-\mathrm{O}-\mathrm{C}$ group of hetrocyclic furan ring. On complexation, this band is undisturbed, indicating noninvolment of oxygen in coordination. Absorption due to the sulphato group in $\mathrm{CO}$ (II) complex $\left[\mathrm{CO}\left(\mathrm{MB}_{2}\right) \mathrm{SO}_{4}\right]$ observed at $1097 \mathrm{~cm}^{-1}$ and 620 $\mathrm{cm}^{-1}$ indicating the coordination through sulphate ion. The other IR band in complexes $\left[\mathrm{CO}\left(\mathrm{MB}_{2}\right) \mathrm{Cl}_{2}\right]$ and $\left[\mathrm{CO}\left(\mathrm{MB}_{2}\right)\right.$ $\mathrm{SO}_{4}$ ] observed at $320 \mathrm{~cm}^{-1}$ and $370 \mathrm{~cm}^{-1}$ suggests the $v \mathrm{M}-\mathrm{Cl}$ and $v M-S$ modes respectively. The above information indicate that the ligand behaves as bidentate with $\mathrm{NN}$ sites respectively.

Table 3: Electronic Spectral Data and Computed Values of Spectral Parameters for CO (II) Complexes

\begin{tabular}{|c|c|c|c|c|c|c|}
\hline \multirow[b]{2}{*}{$\begin{array}{c}\text { S. } \\
\text { No. }\end{array}$} & \multirow{2}{*}{\multicolumn{2}{|c|}{ Spectral Data and Parameters }} & \multicolumn{4}{|c|}{ Complexes } \\
\hline & & & \multirow{2}{*}{$\begin{array}{c}\mathbf{C O} \\
\left(\mathbf{M B}_{\mathbf{1}}\right)_{\mathbf{2}} \mathbf{C l}_{\mathbf{2}} \\
8050\end{array}$} & \multirow{2}{*}{$\begin{array}{c}\begin{array}{c}\mathrm{CO} \\
(\mathrm{MB1})_{2} \mathbf{S O}_{4}\end{array} \\
8180 \\
\end{array}$} & \multirow{2}{*}{$\begin{array}{c}\mathbf{C O} \\
\left(\mathbf{M B}_{\mathbf{2}}\right)_{\mathbf{2}} \mathbf{C l}_{\mathbf{2}} \\
8220 \\
\end{array}$} & \multirow{2}{*}{$\begin{array}{c}\mathbf{C O} \\
\left(\mathbf{M B}_{2}\right)_{2} \mathbf{S O}_{\mathbf{4}} \\
8300\end{array}$} \\
\hline \multirow{3}{*}{1} & \multirow{3}{*}{ Observed Spin Allowed Transitions (cm-1) } & $v_{1}$ & & & & \\
\hline & & $v_{2}$ & 17200 & 17500 & 17850 & 17700 \\
\hline & & $v_{3}$ & 19800 & 19850 & 20030 & 19750 \\
\hline \multirow{2}{*}{2} & \multirow{2}{*}{ Racah Parameters from Numerical Fitting (cm-1) } & $\mathrm{B}$ & 857 & 854 & 865 & 837 \\
\hline & & $\mathrm{C}$ & 1726 & 1792 & 1786 & 1866 \\
\hline \multirow{2}{*}{3} & \multirow{2}{*}{ Slator Condon Parameters (cm-1) } & $\mathrm{f}^{2}$ & 1103.55 & 1110 & 1120.1 & 1103.6 \\
\hline & & $\mathrm{f}^{4}$ & 49.31 & 51.2 & 51.02 & 53.31 \\
\hline 4 & Crystal Field Parameters from Numerical Fitting $(\mathrm{cm}-1)$ & $10 \mathrm{Dq}$ & 9150 & 9320 & 9360 & 9400 \\
\hline 5 & Crystal Fiield and nephelauxetic Parameters for the ligands used & $\mathrm{f}$ & 1016.66 & 1035.55 & 1040 & 1044.44 \\
\hline
\end{tabular}




\begin{tabular}{|c|c|c|c|c|c|c|}
\hline & in the complexes (cm-1) & $\mathrm{h}$ & 0.5 & 0.541 & 0.458 & 0.583 \\
\hline \multirow{2}{*}{6} & \multirow{2}{*}{ Nephelauxatic ratio and (\%) covalence character } & $\beta$ & 0.88 & 0.87 & 0.89 & 0.86 \\
\cline { 3 - 7 } & \multirow{2}{*}{7} & $\beta \%$ & 12 & 13 & 11 & 14 \\
\hline \multirow{2}{*}{ Ratio between n1,n2n3 } & $v^{3} / v^{1}$ & 2.45 & 2.42 & 2.43 & 2.37 \\
\cline { 3 - 7 } & Mean Pairing Energy & $v^{3} / v^{2}$ & 1.15 & 1.13 & 1.13 & 1.11 \\
\hline 8 & Exact Spin Pairing Energy & $\pi$ & 21715.95 & 24319.39 & 24401.36 & 24650.38 \\
\hline 9 & & $\mathrm{P} / \mathrm{B}$ & 1.22 & 1.25 & 1.24 & 1.3 \\
\hline
\end{tabular}

Table 4: Infrared Spectra Data (in $\mathrm{cm}^{-1}$ ) of Mannich Bases and their CO (II) Metal Complexes

\begin{tabular}{|c|c|c|c|c|c|c|c|c|c|c|c|}
\hline S. $\mathbf{N}$. & Ligand/Complex & n-CH $-\mathrm{CH}-$ & v-CO-NH- & nasy-SO & $\mathrm{n}-\mathrm{SO}_{2}-\mathrm{NH}$ & nsym-SO & nC-O-C & nM-N & nM-O & $\mathrm{nCl}$ & nM-S \\
\hline \multirow{3}{*}{1} & $\mathrm{MB}_{1}$ & $3380 \mathrm{~b}$ & $1705 \mathrm{w}$ & $1334 \mathrm{~m}$ & - & $1150 \mathrm{~m}$ & $1268 \mathrm{~s}$ & - & - & - & - \\
\hline & $\mathrm{CO}\left(\mathrm{MB}_{1}\right) \mathrm{CI}_{2}$ & $3392 b$ & $1706 \mathrm{~m}$ & $1324 \mathrm{~m}$ & - & $1154 \mathrm{~s}$ & $1230 \mathrm{~m}$ & $541 \mathrm{~s}$ & $682 \mathrm{~m}$ & $310 \mathrm{w}$ & - \\
\hline & $\mathrm{CO}\left(\mathrm{MB}_{1}\right) \mathrm{SO}_{4}$ & $3422 \mathrm{~m}$ & $1706 \mathrm{~s}$ & $1323 \mathrm{~s}$ & - & $1153 \mathrm{~m}$ & $1244 \mathrm{~m}$ & $540 \mathrm{w}$ & $681 \mathrm{~s}$ & - & $339 \mathrm{~m}$ \\
\hline \multirow{3}{*}{2} & $\mathrm{MB}_{2}$ & $3350 \mathrm{~b}$ & - & $1339 w$ & $3269 w$ & $1152 \mathrm{~s}$ & $1047 \mathrm{~m}$ & - & - & - & - \\
\hline & $\mathrm{CO}\left(\mathrm{MB}_{2}\right) \mathrm{CI}_{2}$ & $3407 b$ & - & $1338 b$ & - & $1152 \mathrm{~m}$ & $1043 \mathrm{~m}$ & $542 \mathrm{~s}$ & - & $320 \mathrm{~m}$ & - \\
\hline & $\mathrm{CO}\left(\mathrm{MB}_{2}\right) \mathrm{SO}_{4}$ & $3384 b$ & - & $1336 b$ & - & $1153 \mathrm{~m}$ & $1040 \mathrm{w}$ & $540 \mathrm{~s}$ & - & - & $370 \mathrm{w}$ \\
\hline
\end{tabular}

\section{References}

1. Rajiv D, Suman S, Sonmane SK, Shrivastava SK. Pharmacological heterocycles Scaffold: A Review. Advantages in Biological Research 2011;5(3):120-144.

2. Mounika K, Pragathi A, Gyanakumari C. Synthesis, Characterisation and Biological activity of a Sciff base derived from 3-ethoxy salicylaldehyde and 2-aminobenzoic acid and its transition metal complexes, Journal of Scientific Research 2010;2(3):513-524.

3. Neelakanthan MA, Essakkiammal M, Marriapan SS, Dharmaraja J, Jeyakumar T. Synthesis, Characterisation and biological activities of some Sciff base metal complexes, Indian J Pharm Sci 2010;72(2):216-222.

4. Valverde MG, Torroba T. Sulphur Nitrogen Heterocyclic Molecules 2005;10:318-320.

5. Shridhar SK, Ramesh A. Synthesis and Pharmacological activities of Hydrazones. Sciff and Mannich basee of isatin derivatives. Bio Pharm Bull 2001;24:1149-1152.

6. Yogeshwary SD. Synthesis Pyrazinamide Mannich bases and its Anti-T.B. Properties, Pharm Med. Chem Res Lab, BITS Pilani, 2006.

7. Pandey SN, Shriram D. Synthesis, Antibacterial, Antifungal and Anti-HIV activity of Sciff base and Mannich bases derived from Isatin derivatives, Eur J Pharm Sci 1999;9:25-31.

8. Joshi S, Khosla D. In vitro Study of Some medicinaly Important Mannich bases derived from Antitubercular Agent, Bio-org and Med Chem 2004;12:571-576.

9. Rajesh H, Bahekar. Synthesis and Biological Evaluation of Indomethacine Conjugates with Salicylamide and its Mannich bases, Indian Drugs 1998;35(10):648-651.

10. Sarika A. Mixed Ligand Complexes of Fe (III) Containing Pseudohalides, Nitrosyl and Some Mannich bases, Transition Metal Chemistry 2007;32(6):816-821.

11. Raman N, Esthar S, Thangaraja C. J Chem Sci 2004;116(4):209.

12. Chodosh LA, Fire A, Samuels M, Sharp PA. 5, 6dichloro-1-beta-Dribofuranosyl Benzimidazole Inhibits transcription elongation by RNA polymerase II in-vitro. J Bio Chem 1989;26(4):2250-2257.

13. Welage I, Berardi R. Evaluation of omeperazole, lansoperazole, pentoperazole and rabeperazole in the treatment of acid related diseases, J Am pharm Assoc 2000;41(1):52-62.
14. Billups SJ, Carter BL, Mibfradil. A new class of calcium-channel antagonists. The Annals of Pharmacotherapy 1998;32(6):559-571.

15. Mohamad JA, Ahlam JA, Ahmed JA. Synthesis and Structural studies of new Mannich base ligands and their metal complexes, Transition Metal Chemistry 2008;3(7):925-930.

16. Maurya RC, Mishra DD, Jaiswal SK, Mukherjee S. Synthesis and Characterisation of Some novel cyanonitrosyl complexes of chromium (I) with Mannich bases, aromatic aldehyde oximes and syn-phenyl-2pyridylketoxime, Transition Metal Chemistry 1992;17(5):381-383.

17. Sathya D, Kumaran JS, Jayachandramani N. Transition Metal Complexes of N-(1-piperdinosalicylyl) acetamide and their biological Activity, Research Journal of Pharmaceutical, biological and chemical sciences.2012;3(2):905.

18. Sabastiyan A, Yosuva SM. Synthesis, characterization and antimicrobial activity of 2-(dimethylaminomethyl) isoindoline-1,3-dione and its $\mathrm{CO}$ (II) and $\mathrm{Ni}$ (II) complexes. Advances in Applied Science Research 2012;3(1):45-50.

19. Tradwell FP. "Analytical Chemistry", John Wiley and Sons Inc, London 1968.

20. Vogel AI. "A Text Book of Quantitative Analysis", $3^{\text {rd }}$ ed. Longmans, London 1961.

21. Weicher FJ. "Organic Analytical Reagents", D. Von Nostrand (New York) 1965.

22. Weicher FJ. "The Analytical Use of EDTA", D. Von Nostrand (New York) 1965.

23. Kalthif JM, Erving PI. "Treatise on Analytical Chemistry", $2^{\text {nd }}$ ed. Interscience, New York, 1963.

24. Wathrich K. Halv Chem Acta 1965;48:779.

25. Flascuke H. Micro Chem Acta. 1954; 5:361.

26. Patel $\mathrm{P}$, Bhattacharya PK. Indian J Chem 1993;32(A):506.

27. Sakurai T, Nakahara A. Inorg Chim Acta 1981;55:157.

28. Rao CP, Shridhara A, Rao PV, Verghese MB, Rissanen $\mathrm{K}$, Kolehmainen E et al. J Chem Soc, Dalton Trans 1998; 23:83.

29. Verma HS, Pal A, Saxena RC, Katiyar AK. J Indian Chem Soc 1983; 60:83.

30. Koning E, Inorg Chem. 1971; 10:2632. J Inorg Nucl Chem 1972; 34:1173.

31. Lever ABP. J Chem. Soc 1967;A:2041.

32. Koning E. "Structure and Bonding" 1975; 9:175. 
33. Allen GC, Warren KD. "Structure and Bonding" 1971;9:49.

34. Stanley JG, Inorg J. Nucl Chem 1956;2:1

35. Griffith JS, Inorg J. Nucl Chem 1956;2(1):229.

36. Drago RS. "Physical Methods in Chemistry", $2^{\text {nd }}$ ed. Saunders, Philadelphia 1977.

37. Orgel JE. J. Chem Phys 1955;23:1819.

38. Griffit JS. "The theory of Transition Metal Ions", Cambridge Univ. Press 1961.

39. Jorgenson CK. Adv. Chem Phys 1963;5:33.

40. Koning E, Schlafer HL. Z Physik Chem. 1962; 34:355.

41. Nakemato S. "Infrared Spectra of Inorganic and Coordination Compounds", Wiley Interscience, New York 1970.

42. Ferraro JR. "Low Frequency Vibrations of Inorganic and Coordination Compounds", Plenum, New York 1971.

43. Nakamato K. "Infrared Specra of Inorganic and Coordination Compounds," Wiley Interscience, New York 1975, 2.

44. EI-Sonavati AZ, EI-Bindary AA, Mabrouk, EI-Sayed M. Trans Met Chem 1992;17(1):66. 